\title{
Effect of sodium/iodide symporter (NIS)-mediated radioiodine therapy on estrogen receptor-negative breast cancer
}

\author{
CHEN YAO $^{1 *}$, YI PAN $^{2,3^{*}}$, YONGXIN LI $^{1 *}$, XIANGDONG XU ${ }^{1}$, YING LIN $^{1}$, \\ WENJIAN WANG ${ }^{4}$ and SHENMING WANG ${ }^{1}$

\begin{abstract}
${ }^{1}$ Department of Vascular, Thyroid and Breast Surgery, The First Affiliated Hospital, Sun Yat-sen University; ${ }^{2}$ Southern Medical University; ${ }^{3}$ Department of Radiation Oncology, Guangdong General Hospital and Guangdong Academy of Medical Sciences; ${ }^{4}$ Laboratory of the Department of Surgery, The First Affiliated Hospital, Sun Yat-sen University, Guangzhou, Guangdong 510080, P.R. China
\end{abstract}

Received November 28, 2014; Accepted February 5, 2015

DOI: 10.3892/or.2015.3946

\begin{abstract}
Since the sodium/iodide symporter (NIS) stimulates the iodine uptake in normal lactating breast, our study aimed to study the effect of NIS-mediated radioiodide therapy on ER-negative breast cancers. A recombinant lentivirus plasmid encoding the human NIS (hNIS) gene and firefly luciferase (Fluc) was constructed. MDA-MB-231 cells were transfected with the recombinant lentivirus, and the hNIS gene expression was identified by western blot analysis and real-time PCR. Tissue-specific expression of the NIS gene was confirmed by immunohistochemical (IHC) staining. Functional NIS activity in the MDA-hNIS cells was confirmed by the uptake of ${ }^{131} \mathrm{I}$ and cytotoxicity assays. The relative expression level of hNIS mRNA exhibited a 10-fold higher expression in the MDA-hNIS cells compared with the level in the control cells without the endogenous NIS gene. Abundant expression of hNIS protein was noted in the cell membrane compared to the cytoplasm which confirmed the efficient expression of the functional hNIS gene. Iodine uptake into the MDA-hNIS cells was rapid, reaching a maximum after $15 \mathrm{~min}$, followed by a decline. Exposure of the MDA-hNIS cells with ${ }^{131}$ I resulted in a time-dependent reduction in colony formation compared with the survival of the control (MDA) cells. Our results confirmed that NIS overexpression enhances the sensitivity of ER-negative breast cancer cells to radioiodide therapy.
\end{abstract}

Correspondence to: Dr Wenjian Wang, Laboratory of the Department of Surgery, The First Affiliated Hospital, Sun Yat-sen University, Guangzhou, Guangdong 510080, P.R. China

E-mail: wangwenjiang0827@163.com

Dr Shenming Wang, Department of Vascular, Thyroid and Breast Surgery, The First Affiliated Hospital, Sun Yat-sen University, Guangzhou, Guangdong 510080, P.R. China

E-mail: wangshenming0827@163.com

*Contributed equally

Key words: breast cancer, estrogen receptor, radioiodide therapy, NIS, lentiviral vector, ${ }^{131} \mathrm{I}$

\section{Introduction}

Breast cancer is the most common cancer in women, accounting for $23 \%$ of all female cancers around the globe, and its incidence is rising particularly in developing countries (1). Worldwide, it is estimated that more than one million women are diagnosed with breast cancer every year, and more than 400,000 will succumb to the disease (2).

Breast cancer is a heterogeneous disease, and risk factors may be differentially associated with the development of distinct tumor subtypes that manifest different biological behaviors and progression (3). In support of this research, there is growing evidence that known breast cancer risk factors vary according to hormone receptor status and perhaps other pathological characteristics of the disease (4-6).

One major way of defining the type of breast cancer is whether or not it is endocrine receptor (estrogen or progesterone receptor)-positive, HER2-positive, triple-negative (not positive to receptors for estrogen, progesterone or HER2) or triple-positive (positive for estrogen receptors, progesterone receptors and HER2) (7,8). These classifications provide oncologists with valuable information about how the tumor acts and what type of treatments may work best. Generally, surgical and radiation treatments are similar for these different types of breast cancer. Drug treatments, such as chemotherapy, endocrine therapies and other medications, usually vary. Drug treatments are targeted to the specific type of cancer $(9,10)$.

Some breast cancers (estimates range between 10 and $17 \%$ ) are known as 'triple-negative' since they lack estrogen and progesterone receptors and do not overexpress the HER2 protein (11). The majority of breast cancers associated with the gene known as BRCA1 are triple-negative (12). Overall, however, they have a poorer prognosis than other types of breast cancers. To date, no targeted therapies such as tamoxifen or Herceptin have been developed to help prevent recurrence in women with triple-negative breast cancer (13). Cancer experts are studying several promising targeted strategies aimed at triple-negative breast cancer.

Even though surgical intervention combined with radiotherapy, chemotherapy and endocrine therapy has achieved beneficial results in many breast cancer treatments; for some 
patients, particularly estrogen receptor-negative breast cancer patients, the combined treatment is not as promising as treatment for other types of breast cancers. ER-negative breast cancer accounts for approximately one-third of breast cancers, and has a high invasiveness among tumor subtypes and a high relapse rate (14-16). Unfortunately, ER-negative breast cancer is not very sensitive and often responds poorly to endocrine therapy and chemotherapy; thus, the prognosis is significantly worse compared to ER-positive patients (17-19).

Sodium/iodide symporter $\left(\mathrm{Na}^{+} / \mathrm{I}^{-}\right.$symporter, NIS), an intrinsic plasma membrane protein, mediates active iodide transport into the thyroid gland and several extra-thyroidal tissues (19). The uptake of iodine by NIS serves as the basis for thyroid hormone biosynthesis, diagnostic thyroid radionuclide imaging as well as treatment of hyperthyroidism and thyroid cancer by radioactive iodine $(19,20)$. NIS is also detected in the mammary gland, placenta, salivary and digestive gland as well as other types of tissues (19,21-23). Among them, the high expression of NIS in breast cancer is attracting more attention $(24,25)$. However, the relationship between the expression of NIS in ER-negative breast cancer and its clinical significance remains elusive.

The ability of cancerous thyroid cells to actively transport iodine via NIS provides a unique and effective delivery system to detect and target these cells for destruction with therapeutic doses of radioiodide, largely without harming other tissues. Therefore, it seems feasible that radioiodide could be a diagnostic and therapeutic tool for the detection and destruction of other cancers in which NIS is functionally expressed (19).

Radioisotopes $\left({ }^{131} \mathrm{I}\right)$ have been successfully used for several decades to treat thyroid cancer after residues and metastasis (26). The prerequisite for this radioiodide therapy is the existence of NIS, which facilitates the uptake of radioiodide in thyroid cancer cells resulting in $\beta$-ray emissions which cause irreversible DNA damage, leading to cell death (19). With the success of NIS gene cloning and the use of gene transfer technology it has become possible to introduce the NIS gene into non-thyroid tumor cells, so that it has a polyiodides function similar to thyroid tissues (23). An important recent discovery was that NIS is functionally expressed in vivo in transgenic mouse mammary tumors and is immunohistochemically detected in over $80 \%$ of human breast cancers (21), raising the possibility of using radioiodide as a novel therapy for breast cancer. Other iodide-transporting tissues also may upregulate NIS in the process of malignant transformation. It is therefore arguable that extra-thyroidal NIS-expressing cancers could be targeted with ${ }^{131} \mathrm{I}$, if NIS is present and functional.

The cloning of rat NIS (rNIS) (27) and human NIS (hNIS) cDNAs (28), and subsequent generation of anti-NIS antibodies (Abs), have made it possible to examine NIS expression in human tissues and correlate it with I-uptake $(20,29,30)$. Eventually, the radioactive iodine treatment extended to non-thyroid tumors such as breast and colon cancers and malignant-targeted radiation therapy may provide new modalities in cancer therapy $(19,23)$. In view of this, we further explored NIS-mediated ${ }^{131}$ I irradiation in ER-negative breast cancer treatment.

In order to study the effect of NIS-mediated radioiodide therapy in ER-negative breast cancers, we constructed a recombinant lentivirus plasmid encoding the hNIS gene. Since the iodine treatment for breast cancer requires high expression of NIS, we constructed ER-negative breast cancer cell lines by transfecting MDA-MB-231 cells with the recombinant lentivirus stably and efficiently expressing the functional NIS gene. A further analysis of tissue-specific NIS gene expression was carried out by fractionation of the cells into cell membrane and cytoplasm fractions. A western blot analysis carried out with these separated fractions showed that NIS was abundantly overexpressed ( 3 -fold) on the cell membrane compared to the cytoplasm. We further characterized the iodine uptake by these cell lines at different time-points and the effect of NIS overexpression on ${ }^{131}$ I sensitivity in these cancer cells.

\section{Materials and methods}

Breast cancer tissue sample collection and preparation. Tissue and archived paraffin-embedded samples were obtained from patients diagnosed with breast cancer who underwent surgical resection at the Department of Breast Surgery, The First Affiliated Hospital of Sun Yat-sen University, Guangzhou, China. All studies were approved by the Institute Research Medical Ethics Committee of Sun Yat-sen University. All individuals provided informed consent prior to their inclusion in the study.

Immunohistochemical (IHC) analysis of NIS expression in the breast cancer tissues. IHC staining was carried out on formalin-fixed, paraffin-embedded micro-tissue sections (4- $\mu \mathrm{m}$ thick) which were deparaffinized in xylene and rehydrated in decreasing concentrations of ethanol and rinsed in phosphate-buffered saline. The antigen was retrieved with microwave treatment in $10 \mathrm{mM}$ citrate buffer ( $\mathrm{pH} \mathrm{6.0)}$. IHC staining was carried out using the EnVision ${ }^{\mathrm{TM}}$ kit (Dako) following the manufacturer's instructions. The endogenous peroxidase activity was quenched by $3 \%$ hydrogen peroxide for $10 \mathrm{~min}$. The sections were incubated in the primary polyclonal rabbit anti-NIS antibody (Santa Cruz Biotechnology) at a dilution of 1:200 for $30 \mathrm{~min}$ at room temperature. In the negative controls, the primary antibody was substituted by normal goat serum. Then the tissue sections were sequentially incubated with ready-to-use horseradish peroxidase (HRP)-immunoglobulin (Evision ${ }^{\mathrm{TM}}$ ) for $30 \mathrm{~min}$ and then were developed with 3'3'-diaminobenzidine (DAB) as a chromogen substrate. The nuclei were counterstained with Meyer's hematoxylin (23).

RNA extraction and quantitative real-time polymerase chain reaction ( $q R T-P C R)$. Total RNA from the breast samples were extracted by TRIzol (Invitrogen). RNA samples from breast cancer and normal breast tissues were pooled in equal amounts in single tubes. The mRNA levels of NIS were examined by real-time PCR. Briefly, complementary DNAs were prepared from the total RNA (10 ng) using the QuantiTect Reverse Transcription kit (Qiagen Inc., Valencia, CA, USA) according to the manufacturer's instructions. Then the RT reaction mixture $(1 \mathrm{ml})$ was subjected to real-time PCR analyses using CFX-96 (Bio-Rad Laboratories, Hercules, CA, USA) according to the manufacturer's instructions. The thermal cycle profile used was incubation at $50^{\circ} \mathrm{C}$ for $2 \mathrm{~min}$ and denaturing at $95^{\circ} \mathrm{C}$ for $10 \mathrm{~min}$, followed by 40 cycles of the amplification step. The 
primer sets used were: forward, 5'-CCATCCTGGATGACAA CTTGG-3' and reverse, 5'-AAAAACAGACGATCCTCATT GGT-3'; QuantiTect Primer assay, QT00044723 for hNIS and QT00079247 for human glyceraldehyde 3-phosphate dehydrogenase (GAPDH) (both from Qiagen Inc.).

Western blot analysis. Proteins were extracted from the breast cancer and normal breast samples. Relative expression levels of NIS and tubulin were detected by SDS-PAGE with the following antibodies according to the manufacturer's instructions: NIS (catalog bs0448R; Bioss, Beijing, China) and tubulin (catalog 1879-1; Cell Signaling Technology, Inc., Danvers, MA, USA) which was used as a loading control. HRP-conjugated anti-rabbit immunoglobulin (catalog A000981; GenScript USA Inc., Piscataway, NJ, USA) was used as the secondary antibody. Finally, protein bands were imaged on X-ray film (Eastman Kodak Co., Rochester, NY, USA) after incubating PVDF membranes (Millipore Corp., Bedford, MA, USA) with enhanced chemiluminescence (ECL) detection reagent (Forevergen Inc, Guangzhou, China).

Construction of the lentiviral vectors overexpressing $h N I S$. To generate the recombinant lentivirus plasmid encoding the hNIS gene, the hNIS gene (Genebank, NM_000453) was cloned into the lentivirus vector [CS-CMVsr39tk-Ifirefly luciferase (Fluc)] (kindly provided by Professor Irene L. Wapnir of Stanford University) at the 5' Nhe1 and 3' BamH1 restriction sites. The NIS gene fragment was ligated to the vector CS-CMVsr39tk-I-Fluc using T4 DNA ligase, generating the CS-CMV-hNIS-I-Fluc plasmid.

Lentivirus infection of ER-negative breast cancer cell lines. The CS-CMV-hNIS-I-Fluc plasmid and packaging helper plasmids, pCMV.R 8.2 and pMD.G, were mixed in a ratio of 9:8:1 and then transfected into 293T cells. The supernatants were collected after $72 \mathrm{~h}$ and assayed for its viral titer. Breast cancer MDA-MB-231 cells (HER2/neu-negative) were seeded in 6-well plates at least $24 \mathrm{~h}$ before infection. Purified virus solution $5 \mu \mathrm{l} / \mathrm{ml}$ of medium was mixed with Polybrene to a final concentration of $10 \mu \mathrm{g} / \mathrm{ml}$ and incubated for $4 \mathrm{~h}$ at $37^{\circ} \mathrm{C}$. The medium was exchanged with fresh medium for an additional $48 \mathrm{~h}$ of incubation. After $48 \mathrm{~h}$ of transfection, the expression of fluorescence was determined to evaluate the infection efficiency. The single clones expressing the NIS gene determined by its fluorescence were subcultured to continue the expansion culture. The cells highly expressing hNIS in the membrane were selected for further studies on the radioiodide uptake and cytotoxicity assays.

In vitro iodide uptake studies. The ER-negative breast cancer cells [MDA-hNIS and MDA (control)] were seeded at a concentration of $5 \times 10^{4}$ cells in 12 -well plates. After an 18- to 24-h incubation period at $37^{\circ} \mathrm{C}$ with $5 \% \mathrm{CO}_{2}$, the medium was aspirated and washed with B-HBSS (buffered Hank's balanced salt solution). Iodide uptake was initiated by adding $500 \mu \mathrm{l}$ HBSS containing $5 \mu \mathrm{Ci} / \mathrm{ml} \mathrm{Na}^{131} \mathrm{I}$ (Shanghai Xinke), and incubated for different time-points from $5 \mathrm{~min}$ to $1 \mathrm{~h}$. At various time-points, the reactions were rapidly terminated by pipetting the radioactive B-HBSS off and washing the cells twice with ice-cold HBSS. Cells were then solubilized by incubation for 20 min with 1\% NP-40 cell lysates in B-HBSS, and accumulated iodide and its radioactivity was measured using a $\gamma$-counter (Shanghai Rihuan).The radioactivity was normalized to the cell number at the time of assay.

Cytotoxic clonogenic assay in ${ }^{131}$ I-treated MDA-MB231 cells. Each group of cells (containing $2 \times 10^{5}$ ), respectively, was exposed to $30 \mu \mathrm{Ci} / \mathrm{ml} \mathrm{Na}^{131} \mathrm{I}$ and incubated in $5 \% \mathrm{CO}_{2}$ at $37^{\circ} \mathrm{C}$ for 2 and $6 \mathrm{~h}$, respectively. The reaction was terminated by removing the medium containing $\mathrm{Na}{ }^{131} \mathrm{I}$ and washing the cells twice with HBSS. The cells then were trypsinized, counted and subsequently cultured with growth medium in 6 -well plates, and the colony formation was assessed after 10 days. Uptake of ${ }^{131} \mathrm{I}$ was confirmed by Geiger Mueller counter before plating. Cells were then fixed in $70 \%$ ethanol and stained with Giemsa staining, and the number of macroscopic colonies was counted. The survival rate was calculated as the percentage of cell colonies in plates treated with ${ }^{131} \mathrm{I}$ compared with those with only HBSS, and the cell survival curves were plotted.

Statistical analysis. All statistical analyses were carried out using the SPSS 13.0 statistical software package. Data are represented as means \pm standard deviation (SD). $\mathrm{P}<0.05$ was considered to indicate a statistically significant result.

\section{Results}

The level of NIS expression in the breast cancer tissues compared to the normal breast tissues. The NIS protein and mRNA expression levels were confirmed by performing western blot analysis and qRT-PCR. NIS protein $(\sim 75 \mathrm{kDa})$ was expressed in the normal breast tissues, ER-positive and ER-negative breast cancer tissues as well as the thyroid tissues. Tubulin ( $55 \mathrm{kDa})$ was used as an internal control. The NIS protein expression was quantified (Fig. 1A) and the expression of NIS protein in the breast cancer tissues (both in ER-negative or ER-positive) was significantly higher compared to that in the adjacent tissues while significantly lower compare to that in the thyroid tissues (Fig. 1B).

Relative expression of NIS mRNA showed significantly increased expression in the ER-negative cells compared to that in the normal cells. The level of expression of NIS mRNA between normal cells and ER-negative cells was significant (Fig. 1C).

NIS protein expression in the breast cancer tissues is localized in the cytoplasm. IHC detection of cells was carried out for NIS expression in various tissues including ER-positive, ER-negative, thyroid and normal control cells (adjacent tissues) as described previously (43). Compared to the control cells, ER-positive and ER-negative breast cancer tissues showed expression of NIS proteins (brown-colored particles after staining) which was mainly concentrated in the cytoplasm (Fig. 2A). In the thyroid tissues, the NIS proteins were expressed mainly in the cell membrane. The $\mathrm{Na}^{+} / \mathrm{I}^{-}$symporter (NIS) is an integral plasma membrane glycoprotein that mediates active iodine transport into thyroid follicular cells, the first step in thyroid hormone biosynthesis (31). NIS-mediated thyroidal iodine transport from the bloodstream to the colloid 
A

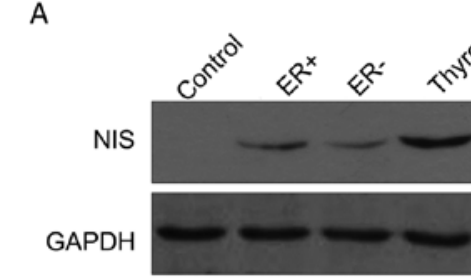

C

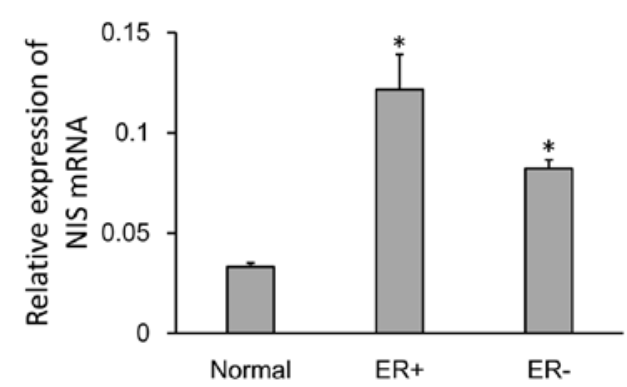

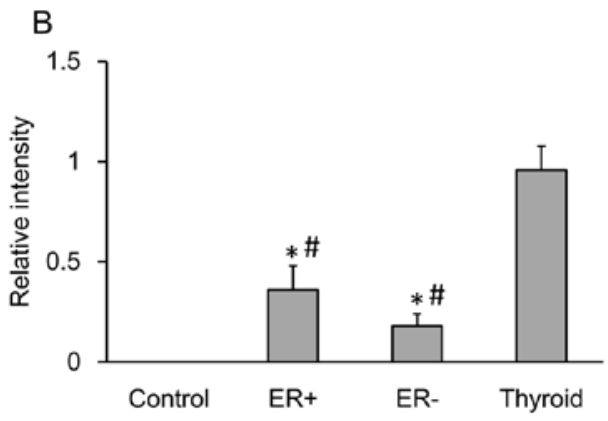

Figure 1. NIS expression. (A) Western blotting and (C) qRT-PCR detect NIS protein and mRNA expression in adjacent tissues (normal), ER-positive breast cancer (ER $)$, ER-negative breast cancer (ER') and thyroid tissues (thyroid). qRT-PCR experiments were performed in triplicate. (B) Relative expression of NIS protein in western blotting was quantified using Image $\mathbf{J}$ software. All experiments were performed in triplicate, and the results are expressed as means $\pm \mathrm{SD}$ analyzed with AVOVA. ${ }^{\mathrm{P}<0.05}$ vs. normal, ${ }^{,} \mathrm{P}<0.05$ vs. thyroid. NIS, sodium/iodide symporter.

A

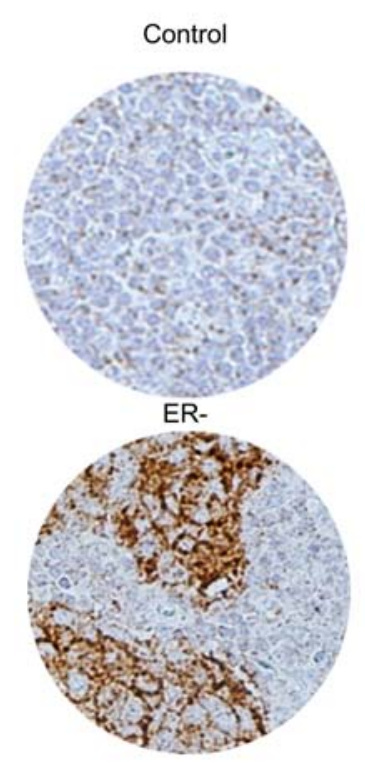

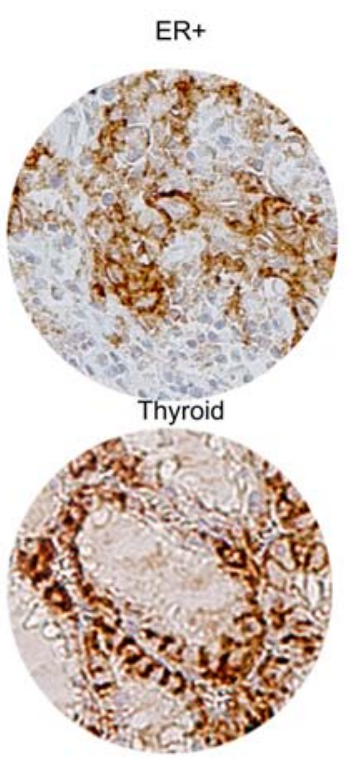

B

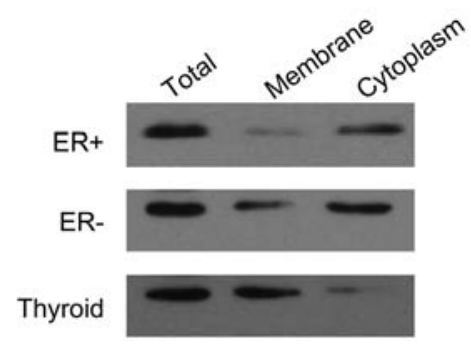

- Total aMembrane acytoplasm

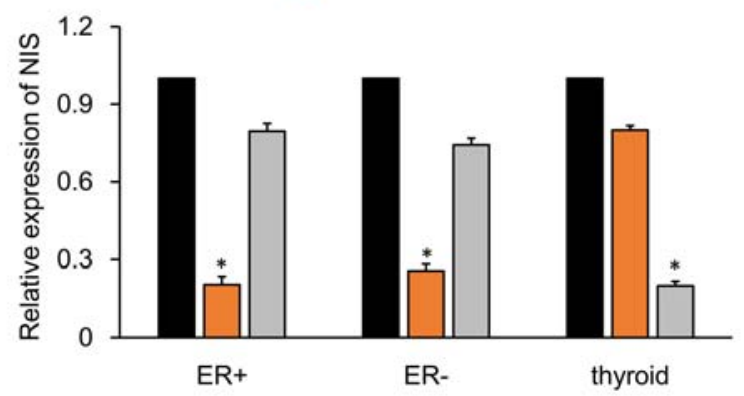

Figure 2. NIS protein expression in breast cancer tissues is localized in the cytoplasm. (A) Immunohistochemical (IHC) detection of NIS protein in adjacent tissues as control cells, ER-positive and ER-negative breast cancer and thyroid tissues. (B) Western blot and quantitative analysis of NIS protein expression in the separate components of cancer cells (cytoplasm and cell membrane) to show the intracellular localization in ER-positive breast cancer (ER+), ER-negative breast cancer (ER-) and thyroid tissues (thyroid). Results are expressed as means \pm SD of 3 independent experiments analyzed with ANOVA. ${ }^{*} \mathrm{P}<0.05$ vs. total NIS, sodium/iodide symporter.

is a vectorial process made possible by the selective targeting of NIS to the basolateral membrane (19).

In addition, we subjected the breast cancer cell lines (ER-positive and ER-negative) to cell fractionation and analyzed the NIS expression using western blot analysis (Fig. 2B). NIS protein expression in the breast cancer cells was localized poorly in the membrane $(\leq 25 \%)$, while in the thyroid tissue membranes it was highly concentrated $(\geq 70 \%)$. These results suggest that NIS is mainly expressed in the cytoplasm, so that breast cancer may not be as effective as the thyroid in regards to the uptake of radioactive iodine.

Breast cancer cell lines overexpressing NIS protein. Patients with breast cancer may benefit from radioiodine therapy if NIS expression/activity can be increased in the malignant tissues to levels sufficient for therapy (32). Findings (33) have shown that retinoic acid (RA) induces the endogenous NIS expression in many malignant cells, particularly in ER-positive breast cancer 
A

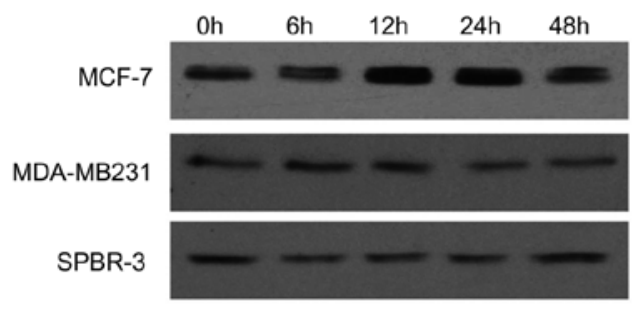

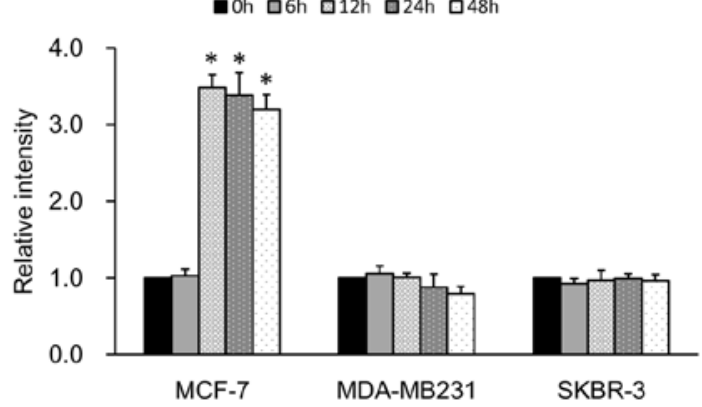

Figure 3. Expression of NIS proteins in ER-positive and ER-negative cell lines. (A) Western blot analysis shows the endogenous NIS protein expression in ER-positive cell line, MCF-7 and ER-negative cell lines, MDA-MB-231 and SPBR-3 at different time-points after RA induction from 0 to 48 h. At 12 and $24 \mathrm{~h}$ of growth, the ER-positive cell line, MCF-7, showed high levels of NIS expression. The NIS protein expression in both the ER-negative cell lines was the same at every time-point after RA induction. (B) Relative expression of NIS protein in western blotting from 3 independent experiments was quantified using Image $\mathrm{J}$ software. Results are expressed as means $\pm \mathrm{SD}$ analyzed with AVOVA. ${ }^{*} \mathrm{P}<0.05$. NIS, sodium/iodide symporter; RA, retinoic acid.

A

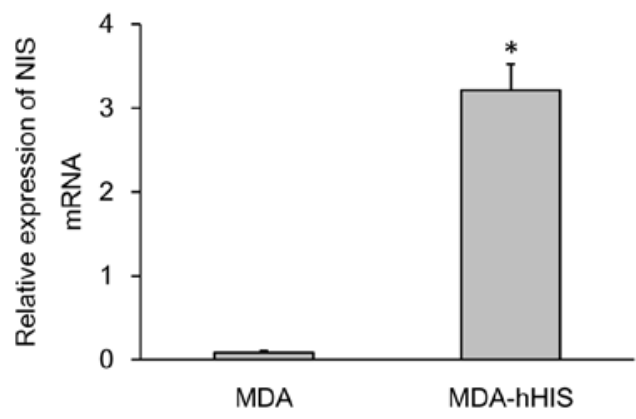

B
C
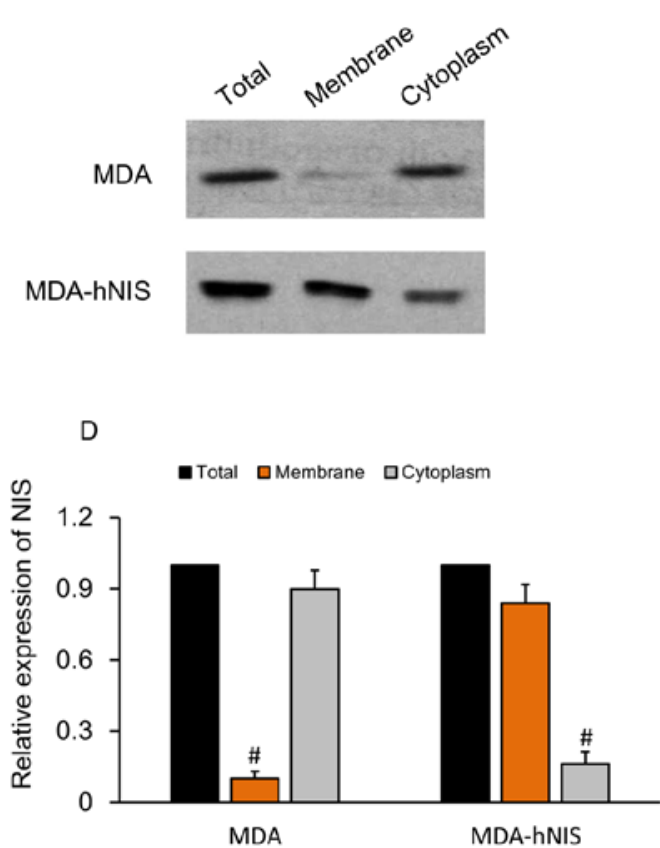

Figure 4. NIS overexpression in the ER-negative cell line MDA-MB-231. (A) qRT-PCR analysis. Relative expression of hNIS mRNA in normal cell lines (MDA) and a transduced ER-negative cell line of breast cancer overexpressing NIS (MDA-hNIS). MDA-hNIS cells showed a 10-fold higher expression of NIS mRNA compared with the control cells. (B) Western blot analysis to quantify the NIS protein. The NIS protein expression in the MDA-hNIS cells was consistent with the NIS mRNA expression in the normal cells. Tubulin was used as an internal control for western blotting. Experiments were performed in triplicate. (C) Western blot analysis of NIS expression in the cell membrane and cytoplasm. Total, is the total protein expressed in the cytoplasm and cell membrane. Data were normalized to total protein. (D) Relative expression of hNIS in the cell membrane and cytoplasm of the transduced cell lines. Data were normalized to total protein. Results are expressed as means \pm SD of 3 independent experiments analyzed with ANOVA. ${ }^{*} \mathrm{P}<0.05$ vs. MDA, $\mathrm{P}<0.05$ vs. total. NIS, sodium/iodide symporter; hNIS, human NIS.

cell lines such as MCF-7. In our study, we found the results of NIS protein expression in ER-positive and ER-negative cell lines in accordance with the previous studies. The levels of expression of NIS in the ER-negative cell lines MDA-MB-231 and SPBR-3 were very low compared with the high expression levels of RA-induced NIS protein in the MCF-7 cells at different time-points from 0 to $48 \mathrm{~h}$ (Fig. 3). Therefore, we constructed a lentivirus vector to introduce the exogenous hNIS gene into the MDA-MB-231 cell line which can upregulate the NIS expression more efficiently.
Construction of ER-negative breast cancer cell line, $M D A-h N I S$ stably expressing the NIS gene. To characterize and identify the capacity of the MDA-hNIS cell line to overexpress the NIS gene, qRT-PCR to determine the mRNA expression level and western blot analysis to determine protein expression level were carried out, and the results were compared with the control cell lines.

The relative expression levels of hNIS mRNA showed a 10-fold higher expression in the MDA-hNIS cells when compared with the control cells without the endogenous NIS 


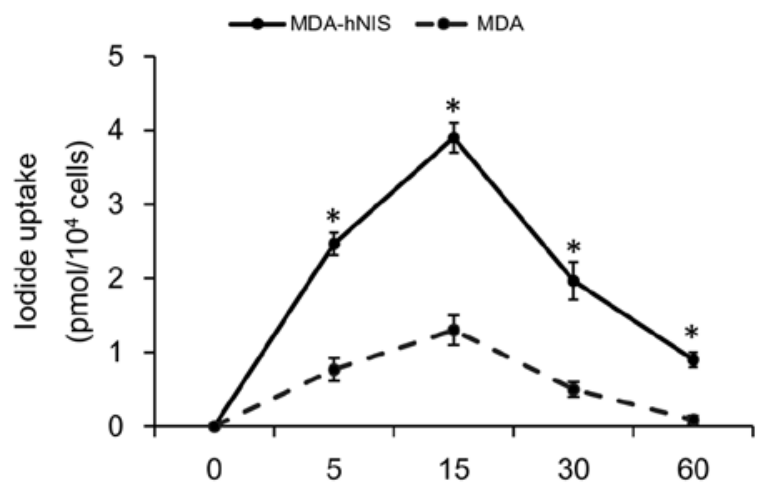

Figure 5. Kinetics of ${ }^{131}$ Iodide uptake in the MDA-hNIS and MDA-MB-231 (MDA) cells at different time-points. Iodine uptake was inititated by incubating MDA-hNIS cells with $\mathrm{Na}^{131} \mathrm{I}$ at $37^{\circ} \mathrm{C}$ for $60 \mathrm{~min}$. The reactions were terminated at the indicated times, and the content of iodide in the cells was determined. MDA-MB-231 (MDA) cells were used as a negative control. Results are expressed as means \pm SD of 3 independent experiments analyzed with ANOVA. " $\mathrm{P}<0.05$ vs. MDA. hNIS, human NIS; NIS, sodium/iodide symporter.

gene (Fig. 4A). The hNIS protein expression level was also significantly higher in the MDA-hNIS cells compared to that in the control cells (Fig. 4B).

A further analysis of tissue-specific NIS gene expression was carried out by fractionation of the cells into cell membrane and cytoplasm portions. Western blot analysis (Fig. 4C) and relative expression of the NIS gene (Fig. 4D) carried out with these separated fractions showed that hNIS was abundantly overexpressed on the cell membrane compared to the cytoplasm. The results prompted us to efficiently express the functional hNIS gene.

Effect of NIS overexpression on ${ }^{131}$ I uptake in the MDA-hNIS cells. The functional activity of the NIS protein expression was evident by its cellular uptake of iodine. The estrogen ER-negative cell line, MDA-hNIS overexpressing the NIS protein and control cells MDA-MB-231 (MDA) were cultured in 12-well plates and were subjected to $500 \mu \mathrm{l} \mathrm{HBSS}$ containing $5 \mu \mathrm{Ci} / \mathrm{ml} \mathrm{Na}^{131} \mathrm{I}$. As shown in Fig. 5, iodine uptake into the MDA-hNIS cells was rapid, reaching a maximum after $15 \mathrm{~min}$, followed by a decline (half-life, $3.2 \mathrm{~h}$ ). At $60 \mathrm{~min}$ after the addition of ${ }^{131} \mathrm{I}$, the uptake level was maintained at $25 \%$ of the peak activity. These results show that NIS overexpression in MDA-hNIS cells can increase the uptake of radioiodide compared to the control cells with low NIS expression, and thus validates the functional NIS expression in an ER-negative cell line.

Effect of NIS overexpression on ${ }^{131}$ I sensitivity in the $M D A-h N I S$ cells. The in vitro therapeutic effect of radioiodide was estimated by determining the survival of cells in a cytotoxic clonogenic assay. MDA-hNIS and control cells (MDA) at a concentration of $2 \times 10^{5}$ cells were incubated for 2 and $6 \mathrm{~h}$ with $30 \mu \mathrm{Ci} / \mathrm{ml} \mathrm{Na}^{131} \mathrm{I}$. We used a previously established assay (34) to investigate whether ${ }^{131} \mathrm{I}$ had selective cytotoxic activity upon NIS overexpression in the MDA-hNIS cells compared with the control cells. Cells were exposed to $30 \mu \mathrm{Ci} / \mathrm{ml} \mathrm{Na}{ }^{131} \mathrm{I}$ for 2 and $6 \mathrm{~h}$, and colony formation was assessed after 10 days.

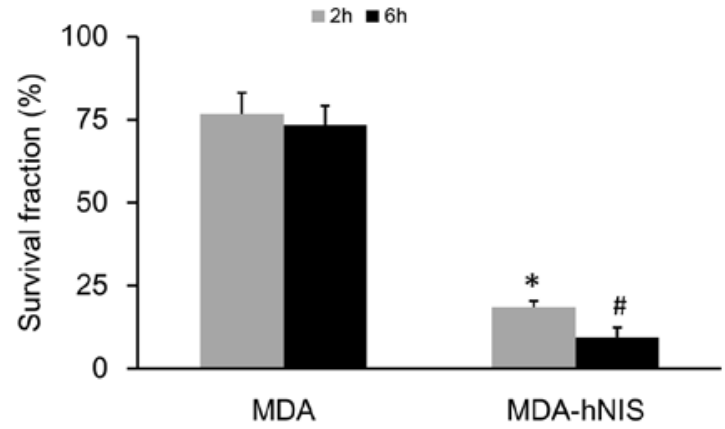

Figure 6. Cell survival rates after $\mathrm{Na}^{131} \mathrm{I}$ treatment. MDA-hNIS and control (MDA) cells were exposed to $30 \mu \mathrm{Ci} / \mathrm{ml} \mathrm{Na}^{131} \mathrm{I}$ for 2 and $6 \mathrm{~h}$, and colony formation was assessed after 10 days. Data are expressed as the percentage of surviving cells. Experiments were performed in triplicate. MDA-MB-231 was used as a negative control. ${ }^{*} \mathrm{P}<0.05$ vs. MDA. " $\mathrm{P}<0.05$ vs. MDA. hNIS, human NIS; NIS, sodium/iodide symporter.

As shown in Fig. 6, the survival rate, based on the clonogenic assay, was markedly reduced in response to ${ }^{131} \mathrm{I}(\mathrm{P}<0.05)$. Exposure of the MDA-hNIS cells to ${ }^{131}$ I resulted in a time-dependent reduction in colony formation of $58 \%$ at $2 \mathrm{~h}$ and $64 \%$ at $6 \mathrm{~h}$, compared with the survival of the control cells (MDA). These results showed that NIS overexpression enhanced the sensitivity of ER-negative breast cancer cells to ${ }^{131} \mathrm{I}$.

\section{Discussion}

ER-negative breast cancer comprises $15-30 \%$ of all breast tumors (depending on the population), and has an earlier age at onset and a worse prognosis compared with ER-positive disease (35). NIS has been widely explored as a potential therapeutic gene for many invasive and malignant cancers. The transfer of the NIS gene using many human and nonhuman vectors into a variety of tumors, including breast (36) and cervical cancer (37) and prostate carcinoma has shown the capacity to confer radioiodide uptake which has emerged as an important radiation therapy for many cancers.

In a preliminary study, we investigated the endogenous NIS gene expression and evaluated its tissue- and site-specific expression by the IHC analysis of tumor tissue samples obtained from patients diagnosed with breast cancer in our hospital. Type-specific breast cancer samples were analyzed for differential expression of the NIS protein. We found significantly higher levels of NIS expression in ER-negative tissues compared to that in the normal tissues and significantly lower levels than thyroid tissues. ER-negative breast cancer tissues showed expression of NIS proteins which was mainly concentrated in the cytoplasm, whereas thyroid cells showed robust expression in the cell membrane, as uptake of iodine by NIS serves as the basis for thyroid hormone biosynthesis.

We observed a markedly low expression of NIS protein in the membrane of breast cancer cells $(\leq 25 \%)$, while in the thyroid tissue membranes it was highly concentrated $(\geq 70 \%)$. These results suggest that NIS is mainly expressed in the cytoplasm, so that breast cancer may not be as effective as the thyroid in uptake of radioactive iodine. The likelihood of iodine transport activity is enhanced whenever NIS is immunohistochemically demonstrated in the plasma membrane. Cell membrane immunoreactivity was not observed in other 
normal or benign breast tissues, with the exception of gestational or lactating samples (23).

Other reasons may also be anticipated for the reduced uptake of iodine in breast cancer cells, due to reduced expression of NIS in breast cancer cells. In a previous study, NIS expression was demonstrated by RT-PCR in 2 of 2 fibroadenomata and 6 of 7 breast carcinoma messenger ribonucleic acid isolates. The authors also demonstrated a significantly higher mean total tissue iodine level ( $80.9 \pm 9.5 \mathrm{ng} \mathrm{I} / \mathrm{mg}$ protein) in 23 benign tumors (fibroadenomata) than those in 19 breast cancers taken from either the tumor $(18.2 \pm 4.6 \mathrm{ng} \mathrm{I} / \mathrm{mg})$ or morphologically normal tissue taken from within the tumor-bearing breast (38). These authors suggested that antibody-mediated inhibition played a major role in the inhibition of ${ }^{125}$ I uptake into NIS-transfected $\mathrm{CHO}$ cells, as these responses were mediated by serum from breast cancer patients compared to normal female controls.

We hypothesized that the low expression of NIS protein in the cell membrane of ER-negative cancer cells may be a possible reason for the reduced susceptibilty to radioiodide therapy in this subgroup of cancer patients. Hence, we constructed a lentivirus vector to introduce the exogenous hNIS gene into the ER-negative cell line MDA-MB-231 which can upregulate NIS expression. The relative expression levels of hNIS mRNA showed a 3-fold higher expression in the MDA-hNIS cells compared with the control cells without the endogenous NIS gene. The NIS protein was also significantly higher and concentrated in the cell membrane compared to the cytoplasm.

Functional NIS activities following ${ }^{131}$ I uptake in MDA-hNIS cells when analyzed, showed a remarkable increase in uptake, reaching a maximum within $15 \mathrm{~min}$, followed by a decline in $1 \mathrm{~h}$. After $1 \mathrm{~h}$ of addition of ${ }^{131} \mathrm{I}$, the uptake level was maintained at $25 \%$ of the peak activity. These results showed that NIS overexpression in the MDA-hNIS cells increased the uptake of radioiodide compared to the control cells with low NIS expression and thus validates the functional NIS expression in ER-negative cell lines. Finally, the exposure of MDA-hNIS cells to ${ }^{131}$ I resulted in a time-dependent reduction in colony formation by $58 \%$ at $2 \mathrm{~h}$ and $64 \%$ at $6 \mathrm{~h}$, compared with the survival of the control cells (MDA) which indicated that NIS overexpression enhanced the sensitivity to ER-negative breast cancer cells.

The NIS gene is well-known for its advantage as a reporter gene in the early diagnosis of many carcinomas. In a previous study (39), ${ }^{131}$ I SPECT revealed a clear image of recombinant baculovirus-infected tumors in vivo, and uptake of ${ }^{131}$ I in tumors was quantified which suggests that the NIS gene would be a promising tool for non-invasive monitoring of vector-mediated gene expression in vivo. Many studies have demonstrated a beneficial response to NIS-based radioiodide therapy in various tumors using tissue-specific promoters, including various cancer markers such as prostate-specific antigen (40), carcinoembryonic antigen (41) and calcitonin (42). However, some specific promoters exhibit lower activity levels than those of non-specific promoters, such as the CMV promoter. We found that following the use of lentivirus-mediated hNIS gene expression in an ER-negative cell line (MDA-hNIS), the iodine uptake assay demonstrated robust and functional NIS activity mediated by the CMV promoter. Moreover, the increased uptake of radioiodide resulted in a marked reduction in the survival rate of ER-negative breast cancer cells.
In conclusion, the present study is a novel method of upregulating the NIS gene expression in ER-negative breast cancer cells using a mammalian lentiviral vector, in order to increase the uptake of radioiodide and to reduce the survival rate of breast tumor cells in ER-negative breast cancer. The potential advantage of radiation inducible genetic constructs has been demonstrated in the so called 'genetic radiotherapy' strategy. The use of radioisotopes that accumulate in tumors offers an advantage for selective induction of exogenous genes. Our research suggests the development of a genetic radiation therapy by boosting NIS expression in ER-negative breast cancer tissues to increase the uptake of radioiodide and increase the susceptibility to radiation therapy for the treatment of breast cancer. This strategy may also prevent metastasis at an early stage in ER-negative breast cancer patients. The clinical applications of hNIS gene transfer is most promising to facilitate radioiodine ablation of locally invasive cancer cells that cannot be completely resected surgically. However, to fullfill this goal many issues need to be resolved, such as selective cytotoxicity in breast cancer cells by careful design and performing in vivo assays in experimental animal models.

\section{Acknowledgements}

The authors thank their colleagues who helped with the outcome data collection. This study was supported by Specialized Scientific Research Fund for the Young Teachers Program of the Sun Yat-Sen University (09ykpy45), Guangdong Natural Science Foundation (S2011010000791) and Guangdong Medical Research Foundation (A2011026). We are grateful to 91SCI Company for language editing assistance.

\section{References}

1. El Saghir NS, Khalil MK, Eid T, El Kinge AR, Charafeddine M, Geara F, Seoud M and Shamseddine AI: Trends in epidemiology and management of breast cancer in developing Arab countries: a literature and registry analysis. Int J Surg 5: 225-233, 2007.

2. Tfayli A, Temraz S, Abou Mrad R and Shamseddine A: Breast cancer in low- and middle-income countries: an emerging and challenging epidemic. J Oncol 2010: 490631, 2010.

3. Garcia-Closas M and Chanock S: Genetic susceptibility loci for breast cancer by estrogen receptor status. Clin Cancer Res 14: 8000-8009, 2008.

4. Ma H, Bernstein L, Pike MC and Ursin G: Reproductive factors and breast cancer risk according to joint estrogen and progesterone receptor status: a meta-analysis of epidemiological studies. Breast Cancer Res 8: R43, 2006.

5. Reeves GK, Beral V, Green J, Gathani T and Bull D; Million Women Study Collaborators: Hormonal therapy for menopause and breast-cancer risk by histological type: a cohort study and meta-analysis. Lancet Oncol 7: 910-918, 2006.

6. Althuis MD, Fergenbaum JH, Garcia-Closas M, Brinton LA, Madigan MP and Sherman ME: Etiology of hormone receptordefined breast cancer: a systematic review of the literature. Cancer Epidemiol Biomarkers Prev 13: 1558-1568, 2004.

7. Nakagawa M, Bando Y, Nagao T, Takai C, Ohnishi T, Honda J, Moriya T, Izumi K, Takahashi M, Tangoku A, et al: Among triple-negative breast cancers, HER2(0) breast cancer shows a strong tendency to be basal-like compared with HER2(1+) breast cancer: preliminary results. Breast Cancer 19: 54-59, 2012.

8. Vaklavas C and Forero-Torres A: How do I treat 'triple-negative' disease. Curr Treat Options Oncol 12: 369-388, 2011.

9. Berry DA, Cirrincione C, Henderson IC, Citron ML, Budman DR, Goldstein LJ, Martino S, Perez EA, Muss HB, Norton L, et al: Estrogen-receptor status and outcomes of modern chemotherapy for patients with node-positive breast cancer. JAMA 295: 1658-1667, 2006. 
10. Altman MB, Flynn MJ, Nishikawa RM, Chetty IJ, Barton KN, Movsas B, Kim JH and Brown SL: The potential of iodine for improving breast cancer diagnosis and treatment. Med Hypotheses 80: 94-98, 2013

11. Blows FM, Driver KE, Schmidt MK, Broeks A, van Leeuwen FE, Wesseling J, Cheang MC, Gelmon K, Nielsen TO, Blomqvist C, et al: Subtyping of breast cancer by immunohistochemistry to investigate a relationship between subtype and short and long term survival: a collaborative analysis of data for 10,159 cases from 12 studies. PLoS Med 7: e1000279, 2010.

12. Chu KC and Anderson WF: Rates for breast cancer characteristics by estrogen and progesterone receptor status in the major racial/ethnic groups. Breast Cancer Res Treat 74: 199-211, 2002.

13. Argiris A, Wang CX, Whalen SG and DiGiovanna MP Synergistic interactions between tamoxifen and trastuzumab (Herceptin). Clin Cancer Res 10: 1409-1420, 2004.

14. Madsen MW and Briand P: Relationship between tumorigenicity, in vitro invasiveness, and plasminogen activator production of human breast cell lines. Eur J Cancer 26: 793-797, 1990.

15. Thompson EW, Paik S, Brünner N, Sommers CL, Zugmaier G Clarke R, Shima TB, Torri J, Donahue S, Lippman ME, et al: Association of increased basement membrane invasiveness with absence of estrogen receptor and expression of vimentin in human breast cancer cell lines. J Cell Physiol 150: 534-544, 1992.

16. Sommers CL, Byers SW, Thompson EW, Torri JA and Gelmann EP Differentiation state and invasiveness of human breast cancer cell lines. Breast Cancer Res Treat 31: 325-335, 1994.

17. Skoog L,Humla S, Axelsson M,Frost M,Norman A,Nordenskjöld B and Wallgren A: Estrogen receptor levels and survival of breas cancer patients. A study on patients participating in randomized trials of adjuvant therapy. Acta Oncol 26: 95-100, 1987.

18. Sandelin K, Skoog L, Humla S and Farnebo LO: Oestrogen, progesterone, and glucocorticoid receptors in normal and neoplastic parathyroid glands. Eur J Surg 158: 467-472, 1992.

19. Dohán O, De la Vieja A, Paroder V, Riedel C, Artani M, Reed M Ginter CS and Carrasco N: The sodium/iodide symporter (NIS): characterization, regulation, and medical significance. Endocr Rev 24: 48-77, 2003.

20. Chung JK: Sodium iodide symporter: its role in nuclear medicine J Nucl Med 43: 1188-1200, 2002.

21. Tazebay UH, Wapnir IL, Levy O, Dohan O, Zuckier LS, Zhao QH, Deng HF, Amenta PS, Fineberg S, Pestell RG, et al: The mammary gland iodide transporter is expressed during lactation and in breast cancer. Nat Med 6: 871-878, 2000.

22. Mitchell AM, Manley SW, Morris JC, Powell KA, Bergert ER and Mortimer RH: Sodium iodide symporter (NIS) gene expression in human placenta. Placenta 22: 256-258, 2001.

23. Wapnir IL, van de Rijn M, Nowels K, Amenta PS, Walton K, Montgomery K, Greco RS, Dohán O and Carrasco N Immunohistochemical profile of the sodium/iodide symporter in thyroid, breast, and other carcinomas using high density tissue microarrays and conventional sections. J Clin Endocrinol Metab 88: 1880-1888, 2003.

24. Upadhyay G, Singh R, Agarwal G, Mishra SK, Pal L, Pradhan PK, Das BK and Godbole MM: Functional expression of sodium iodide symporter (NIS) in human breast cancer tissue. Breast Cancer Res Treat 77: 157-165, 2003.

25. Kogai T, Taki K and Brent GA: Enhancement of sodium/iodide symporter expression in thyroid and breast cancer. Endocr Relat Cancer 13: 797-826, 2006.

26. Mazzaferri EL: Carcinoma of the follicular epithelium. In: The Thyroid: A Fundamental and Clinical Text. Braverman LE and Utiger R (eds). 8th edition, Lippincott Williams and Wilkins, Philadelphia, PA, pp904-930, 2000.
27. Dai G, Levy O and Carrasco N: Cloning and characterization of the thyroid iodide transporter. Nature 379: 458-460, 1996.

28. Smanik PA, Liu Q, Furminger TL, Ryu K, Xing S, Mazzaferri EL and Jhiang SM: Cloning of the human sodium lodide symporter. Biochem Biophys Res Commun 226: 339-345, 1996.

29. Paire A, Bernier-Valentin F, Selmi-Ruby S and Rousset B: Characterization of the rat thyroid iodide transporter using anti-peptide antibodies. Relationship between its expression and activity. J Biol Chem 272: 18245-18249, 1997.

30. Caillou B, Troalen F, Baudin E, Talbot M,Filetti S, Schlumberger M and Bidart JM: $\mathrm{Na}^{+} / \mathrm{I}^{-}$symporter distribution in human thyroid tissues: an immunohistochemical study. J Clin Endocrinol Metab 83: 4102-4106, 1998

31. Carrasco N: Iodide transport in the thyroid gland. Biochim Biophys Acta 1154: 65-82, 1993.

32. Shen DH, Kloos RT, Mazzaferri EL and Jhian SM: Sodium iodide symporter in health and disease. Thyroid 11: 415-425, 2001.

33. Kogai T, Schultz JJ, Johnson LS, Huang M and Brent GA: Retinoic acid induces sodium/iodide symporter gene expression and radioiodide uptake in the MCF-7 breast cancer cell line. Proc Natl Acad Sci USA 97: 8519-8524, 2000.

34. Mandell RB, Mandell LZ and Link CJ Jr: Radioisotope concentrator gene therapy using the sodium/iodide symporter gene. Cancer Res 59: 661-668, 1999.

35. Campa D, Barrdahl M, Tsilidis KK, Severi G, Diver WR, Siddiq A, Chanock S, Hoover RN, Ziegler RG, Berg CD, et al: A genome-wide 'pleiotropy scan' does not identify new susceptibility loci for estrogen receptor negative breast cancer. PLoS One 9: e85955, 2014.

36. Dwyer RM, Bergert ER, O'connor MK, Gendler SJ and Morris JC: In vivo radioiodide imaging and treatment of breast cancer xenografts after MUC1-driven expression of the sodium iodide symporter. Clin Cancer Res 11: 1483-1489, 2005.

37. Boland A, Ricard M, Opolon P, Bidart JM, Yeh P, Filetti S, Schlumberger $\mathrm{M}$ and Perricaudet $\mathrm{M}$ : Adenovirus-mediated transfer of the thyroid sodium/iodide symporter gene into tumors for a targeted radiotherapy. Cancer Res 60: 3484-3492, 2000.

38. Kilbane MT, Ajjan RA, Weetman AP, Dwyer R, McDermott EW, O'Higgins NJ and Smyth PP: Tissue iodine content and serum-mediated ${ }^{125} \mathrm{I}$ uptake-blocking activity in breast cancer. J Clin Endocrinol Metab 85: 1245-1250, 2000.

39. Zhang M, Guo R, Shi S, Miao Y, Zhang Y and Li B: Baculovirus vector-mediated transfer of sodium iodide symporter and plasminogen kringle 5 genes for tumor radioiodide therapy. PLoS One 9: e92326, 2014.

40. Spitzweg C, O'Connor MK, Bergert ER, Tindall DJ, Young CY and Morris JC: Treatment of prostate cancer by radioiodine therapy after tissue-specific expression of the sodium iodide symporter. Cancer Res 60: 6526-6530, 2000.

41. Scholz IV, Cengic N, Baker CH, Harrington KJ, Maletz K, Bergert ER, Vile R, Göke B, Morris JC and Spitzweg C: Radioiodine therapy of colon cancer following tissue-specific sodium iodide symporter gene transfer. Gene Ther 12: 272-280, 2005.

42. Cengic N, Baker CH, Schütz M, Göke B, Morris JC and Spitzweg C: A novel therapeutic strategy for medullary thyroid cancer based on radioiodine therapy following tissue-specific sodium iodide symporter gene expression. J Clin Endocrinol Metab 90: 4457-4464, 2005.

43. Knostman KA, Cho JY, Ryu KY, Lin X, McCubrey JA, Hla T, Liu CH, Di Carlo E, Keri R, Zhang M, et al: Signaling through 3',5'-cyclic adenosine monophosphate and phosphoinositide-3 kinase induces sodium/iodide symporter expression in breast cancer. J Clin Endocrinol Metab 89: 5196-5203, 2004. 